\title{
Medidas das eficiências térmicas em aquecedores solares: uma alternativa complementar para o ensino de conceitos de física para estudantes das engenharias
}

\section{RESUMO}

Júlio César Penereiro icp@puc-campinas.edu.br 0000-0001-5639-4318

Pontifícia Universidade Católica de Campinas (PUC-SP), Campinas, São Paulo, Brasil.
O presente trabalho descreve a construção de dois coletores solares planos visando um estudo comparativo da eficiência térmica entre eles em função das velocidades do vento. Um coletor foi feito com materiais de baixo custo e de fácil acesso à população, enquanto o outro é um coletor de metal à venda no mercado. O trabalho teve como meta aliar o ensino de física ao conhecimento envolvido na construção e funcionamento de um sistema de aquecimento solar de água. Trabalhou-se de forma prática com os conceitos de temperatura, irradiação solar, calor, eficiência térmica, dentre outros. Para tanto, desenvolveu-se um sistema automático de medidas de temperaturas, radiação solar e velocidade de vento, intermediadas por microcontroladores interfaciados com um microcomputador. Realizou-se o levantamento das curvas-respostas dos coletores devido a influência da velocidade do vento incidente, para medidas das suas eficiências térmicas por absorção de energia solar. Constatou-se que o coletor de metal é $14,4 \%$ mais eficiente que o de baixo custo.

PALAVRAS-CHAVE: Medida de eficiência. Influência do vento. Aquecedor solar de baixo custo. Sistema fechado em aquecedores solares. 


\section{INTRODUÇÃO}

Um dos problemas que caracteriza a sociedade é o grande desperdício de energia. Esse consumo desenfreado de energia traz como consequência uma preocupação constante na produção e/ou geração em grande escala, acarretando uma crescente degradação do meio ambiente. Conscientizar a população a respeito desses problemas e buscar por fontes alternativas de energia são processos importantes, mas que, invariavelmente, podem ocorrer de forma muito lenta. O ideal seria incluir uma política educacional que conscientizasse os cidadãos com relação às questões energéticas e ambientais.

Várias discussões em torno de energias alternativas têm sido alvo de debates devido à preocupação com a demanda energética mundial, que está a caminho da saturação, do alto custo e da escassez. Nos dias de hoje há um interesse na energia solar em virtude das suas diversas vantagens. É disponível, pelo menos em certa medida, em qualquer parte do mundo, em contraste com os combustíveis fósseis (carvão mineral, gás natural e petróleo) e nucleares. A energia solar em si não custa nada e é imune às flutuações dos preços das outras formas de energia. Pode ser usada de várias formas, para fornecer eletricidade, calefação, resfriamento, transporte, iluminação e potência mecânica. A maioria dos métodos de uso da energia solar, mas não todos, geram poucos problemas ambientais (ANEEL, 2013).

No entanto, a energia solar também tem algumas desvantagens. Não é fortemente concentrada, embora seja possível coletar energia solar suficiente para algumas aplicações importantes, em áreas pequenas de terreno, ou de coberturas ou de paredes. Além disso, é uma energia intermitente, com o fluxo interrompido pelas noites e pelos dias nebulosos. Porém, com a tecnologia atual já existem formas convenientes, e muitas vezes baratas, de armazená-la durante estes períodos. Infelizmente, sistemas a base de energia solar requerem um investimento de capital elevado, entretanto os custos de amortização são, com frequência, mais que superados pela economia nos preços da energia.

Os sistemas de aquecimento de água empregando energia solar tiveram sua reputação abalada, por um lado devido ao acesso de pessoas com pouca credibilidade no ramo, e por outro, pelos elevados custos apresentados por aqueles que primavam por produtos de melhor qualidade. Atualmente, somente é possível ter um sistema de aquecimento de água com o uso de coletores solares instalados em residências fazendo investimentos que retornarão em longo prazo, isto é, em quase três a quatro anos. Neste sentido, torna-se importante desenvolver produtos que viabilizem o uso da energia solar térmica para o consumidor através de uma visão econômica de mercado.

A iminência de um problema de crise energética no Brasil aumenta juntamente com o crescente consumo que o país vem apresentando, decorrente, em parte, do aumento populacional e do aumento do padrão de vida de algumas classes sociais. A procura por fontes energéticas alternativas parece ser uma opção para que os brasileiros possam produzir a totalidade da energia aqui consumida. Não obstante, o uso de aquecedores solares em habitações populares e o incentivo ao uso de sistemas que utilizam a energia solar em edificações em geral, constituem-se nas medidas de curto prazo mais apropriadas para iniciar um processo do uso de energias limpas e renováveis com alcance social e econômico 
Do ponto de vista do Ensino de Ciências, o momento atual é bastante propício para se discutir cada vez mais a questão energética dentro e fora da sala de aula, principalmente aquelas que buscam incentivar as pessoas a usarem outras formas de energias renováveis, como a solar, eólica, dentre outras. Neste contexto, as disciplinas de Física possuem uma importante contribuição a dar, em particular no ensino das Engenharias, pois, além de transmitirem o conhecimento da ciência Física, devem preparar seus estudantes para atuar de modo fundamentado, consciente e responsável diante das necessidades e dos limites impostos pela vida atual. Assim, entende-se que o Ensino de Ciências também deve ser pautado na motivação em encontrar soluções arrojadas, além de incentivar o uso de fontes de energias renováveis. Principalmente agora, com a possibilidade da aplicação de novas tecnologias na geração de energia renovável, o que pode representar num importante vetor de desenvolvimento social e econômico para diferentes comunidades, isoladas ou não, de diversas regiões do país.

Este tipo de iniciativa é fundamental para as estratégias que buscam, a partir do comportamento das pessoas, a sustentabilidade do desenvolvimento, além da democratização do acesso à energia em suas formas mais adequadas. A contrapartida de tipo de ação pode estar relacionada a geração de novos empregos, a melhoria da qualidade de vida de milhares de cidadãos, o melhor uso das dimensões continentais e da diversidade de fatores sociais, econômicos e ambientais inerentes ao Brasil.

A necessidade de se criarem incentivos ao uso de aquecedores solares para substituírem os tradicionais chuveiros elétricos nos motivou a desenvolver o presente trabalho. Objetivando a identificação de suas características técnicas e seus parâmetros físicos, trabalhou-se com dois aquecedores diferentes com coletores solares planos: um didático, de baixo custo, feito a partir de perfis extrudados e canos de PVC (cloreto de polivinila) e outro feito em metal, disponível no mercado e comumente usado em residências e comércios. Ambos foram construídos e interligados sobre uma bancada de ensaios onde dados experimentais puderam ser coletados. Visando medir as eficiências térmicas desses aquecedores, instalaram-se sensores digitais de temperaturas em posições estratégicas do fluxo de água, além de um Solarímetro e um Anemômetro, todos acoplados e controlados por um microcomputador para aquisição automática de dados. Essas facilidades permitiram inferir estimativas das eficiências térmicas totais dos dois equipamentos em ensaios independentes e, através das curvas de respostas, foi possível comparar essas medições e o desempenho de cada equipamento.

A proposta aqui apresentada tem o objetivo de motivar e encorajar professores e grupos de estudantes dos diferentes cursos de Engenharias, mas que também pode ser adotada em escolas do Ensino Médio, a usarem uma das formas de energia renovável - a energia solar. Mostra-se que é possível construir em sua instituição ensino, ou até mesmo na sua residência, um pequeno aquecedor solar de água que emprega materiais de baixo custo. Trata-se de uma proposta ousada no sentido de, além do uso de materiais de baixo custo, empregar dispositivos que visam obter medidas de parâmetros físicos para caracterizar a eficiência térmica do equipamento. Neste contexto, a presente proposta pode ser usada para entender e estudar os processos físicos relacionados à termodinâmica, radiação eletromagnética e de um corpo negro, lei de Stefan-Boltzmann, campo magnético 
terrestre, os movimentos da Terra, as estações do ano, o efeito estufa e o aquecimento global, além de ao mesmo tempo valorizar o uso da energia solar.

Alguns trabalhos visando a determinação da eficiência térmica com coletor de baixo custo foram também realizados por outros autores (NIEMEYER, 2006; PEREIRA et al., 2006; NETTO, 2006), no entanto, essas ações abordam linhas de pesquisas diferenciadas da aqui apresentada.

\section{METODOLOGIA}

O trabalho foi realizado no Centro de Ciências Exatas e de Tecnologias (CEATEC) da PUC-Campinas, São Paulo. Para implementação do mesmo foram desenvolvidos dois equipamentos de aquecimento de água por meio da energia solar empregando o tipo passivo direto para o sistema hidráulico. Nele a água é aquecida diretamente pelos painéis solares interligados e sua circulação é realizada por termossifão, ou seja, a diferença de densidade devido à variação de temperatura entre os painéis e o reservatório provoca um gradiente de pressão que coloca o fluído em movimento.

O primeiro equipamento foi construído de forma artesanal sendo a montagem da parte principal do coletor solar plano feito perfis extrudados de PVC e sem cobertura de vidro. No segundo equipamento utilizou-se um coletor de padrão metálico (alumínio e cobre) existente no mercado, porém, neste caso, todo sistema de coleta de radiação solar foi envolvido com uma cobertura de vidro para provocar um efeito estufa interno. As montagens desses equipamentos, em particular do coletor solar de PVC, sobre uma bancada de ensaios, bem como dos sistemas hidráulico e de aquisição de dados, são discutidos em detalhes nas seções subsequentes.

\section{MONTAGEM DOS COLETORES SOLARES}

Os perfis extrudados de PVC, desenvolvido pela "Indústria de Plásticos TWB Ltda.", compõe a parte principal do coletor solar plano de baixo custo. A montagem, realizada de forma artesanal, empregou tubos de PVC com diâmetro de $3 / 4$ de polegada que foram cortados longitudinalmente, de forma que as abas dos perfis de PVC pudessem ser dobradas para dentro ou até mesmo quebradas quando necessário, sendo fixados com um adesivo epóxi marca Araldite (Figura 1a e 1b). Este processo apresenta como vantagem o baixo custo para pequenas quantidades, mas possui como desvantagem a baixa estanqueidade das bordas, pelo fato de serem coladas. O passo seguinte à montagem foi lixar a superfície do coletor plano (Figura 1c) e, com um rolo para garantir uma camada de tinta mais espessa, foi pintado dando três demãos com tinta esmalte sintético de cor preta fosca (Figura 1d).

O dispositivo apresenta facilidade no seu transporte devido as suas dimensões $(1,89 \mathrm{~m} \times 0,90 \mathrm{~m})$ e ao seu peso (aproximadamente 2,37 kg). Após todos os cuidados inerentes do processo de montagem artesanal, o coletor solar plano de baixo custo encontrou-se pronto para ser instalado ao sistema hidráulico. 
Figura 1 - (a) Processo de montagem dos perfis extrudados acoplado ao cano de PVC. (b)

Colagem do cano com a cabeça do coletor. (c) Lixamento e montagem do perfil após colagem das peças. (d) Pintura dos perfis antes de fixá-los na bancada móvel
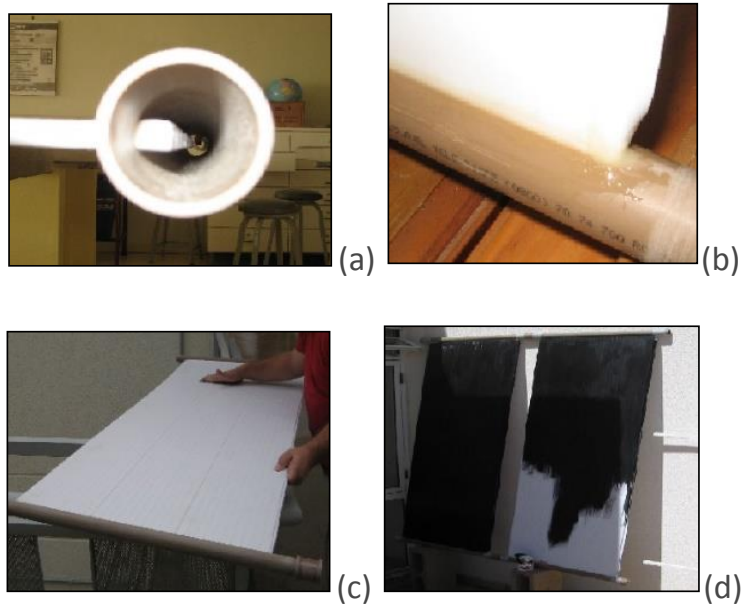

Vale ressaltar que, como citamos anteriormente, o coletor testado no presente trabalho foi fabricado da maneira artesanal, sendo que, durante este processo, verificou-se, por intermédio de um estudo bibliográfico sobre o assunto, que a entidade intitulada Sociedade do Sol ${ }^{1}$ também desenvolve coletores fabricados da maneira alternativa e nos mesmos padrões que se desenvolveu este trabalho. Porém, o processo de desenvolvimento está voltado para atender as necessidades de abastecimento de pessoas de baixa renda, e não para o estudo que aqui se objetivou realizar.

Principalmente devido à resistência e durabilidade, o padrão comercial de coletores solares emprega materiais metálicos, como o alumínio e cobre. Além desses, utiliza-se vidro (normalmente de espessura entre 8,0 a 10,0 mm) na face voltada para o Sol, para criar um ambiente que permita a conservação da radiação solar coletada. Nesse trabalho empregou-se um coletor metálico desenvolvido pela "Empresa Atual Ind. e Com. de Aquecedores Solares Ltda.", modelo "Standard Master Plus". Esse dispositivo possui dimensões são de 1,82 m X 0,91 m e peso de aproximadamente $14,75 \mathrm{~kg}$. Como se constata, as dimensões desse equipamento e o de baixo custo feito em PVC são equivalentes, o que propiciou realizar um estudo comparativo entre ambos.

\section{A BANCADA DE ENSAIOS}

Visando a realização de ensaios experimentais, decidiu-se construir uma montagem utilizando um reservatório plástico constituído de uma caixa d'água em PVC, com capacidade de 100 litros, mas com isolamento térmico. Esse isolamento compõe-se de paredes internas em placas EPS (poliestireno expandido), tudo revestido com plástico negro. Esse dispositivo foi instalado em série com as placas dos coletores solares, como está mostrado na Figura 2. O sistema foi alimentado com água da rede hidráulica, sendo o fluxo hídrico controlado por uma boia d'água de uso comum, por válvulas de agulha e por registros de esfera. 
Figura 2 - Vista da bancada de ensaios em seu formato na fase de construção com os dois coletores solares interligados, o reservatório d' água e um dos dispositivos empregados para aquisição de dados

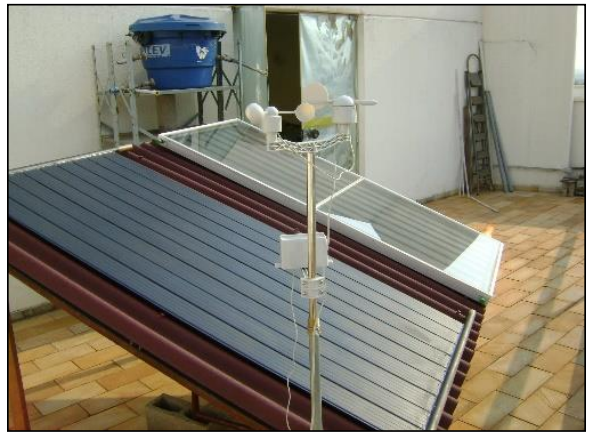

Para as tubulações da bancada de ensaios foram usados tubos de $1 / 2$ polegada, conexões e registros em PVC, pois esses materiais são de fácil aquisição, apresentam baixo custo e possuem boa flexibilidade, facilitando montagens em curvas e desníveis. A única exceção foi realizada junto à tubulação próxima aos coletores onde, nesses casos, foram usadas tubulações maleáveis empregando conduite plástico negro.

Os dois coletores foram fixados sobre um telhado, confeccionado por telhas produzidas com resíduos de fibras vegetais e betume (marca: Onduline), dimensões de 2,00 $\mathrm{m} \times 2,50 \mathrm{~m}$. Por sua vez, esse telhado foi fixado a uma bancada metálica que permite ajustes do ângulo de incidência da radiação solar. Para oferecer uma menor variação do fluxo de radiação ao longo do ano, todo sistema foi ajustado e direcionado para o norte geográfico empregando o método do gnômon, isto é, uso de um ponteiro que marca a altura do Sol pela direção da sombra projetada (OLIVEIRA FILHO; SARAIVA, 2004). Ao mesmo tempo, devido a latitude em que se encontra a cidade de Campinas, SP, empregou-se uma inclinação de $31^{\circ}$ em relação a horizontal. A imagem da Figura 2 mostra alguns detalhes da bancada de ensaios com os dois coletores solares instalados em série sobre ela, além de toda de parte da instrumentação para aquisição de dados que será descrita a seguir.

\section{O SISTEMA DE AQUISIÇÃO DOS DADOS}

Visando as determinações das eficiências térmicas dos coletores solares, realizou-se a instrumentação da bancada de ensaios. Foram empregados seis sensores digitais de temperaturas (modelo: DS1820, faixa de medida: $-55^{\circ} \mathrm{C}$ a $+125^{\circ} \mathrm{C}$; precisão de leitura: $\pm 0,5^{\circ} \mathrm{C}$; fabricante: Dallas Semiconductor, (DALLAS, 2013)), acoplados a uma placa controladora, especialmente desenvolvida, conectada na entrada RS232 de um microcomputador tipo PC (Figura 3a).

Previamente, e de forma separada, realizou-se a calibração de cada sensor através da comparação do sinal adquirido pela leitura no monitor do microcomputador com o valor lido num termômetro de mercúrio, empregando um Becker contendo água que foi aquecida de maneira controlada por meio de um aquecedor elétrico manual. Foram feitas cinco medições para cada um dos quatro 
para cada sensor empregado (Figura 3b). Por meio desse tipo de gráfico foi possível certificar que os todos os sensores DS1820 usados no trabalho são de boa qualidade e estão operando em condições ideais para os intervalos de temperaturas que o equipamento de aquecimento solar de água deve estar operando, garantido, desta forma, que as medidas lidas por cada sensor sejam coerentes.

Após a devida calibração, cada sensor foi inserido no circuito hidráulico por meio de um tubo de PVC no formato de T, com tampa rosqueada pela qual foi feito um furo para a inserção do dispositivo de medição. Para promover a estanqueidade do furo por onde passa a fiação do sensor, foi empregada uma cola epóxi Araldite. A homogeneização da temperatura da água quando em contato com o sensor é feita através do próprio circuito hidráulico devido ao turbilhonamento ocorrido na entrada e na saída, pela movimentação do fluido devido à convergência dos fluxos de cada duto do perfil de PVC. Durante cada ensaio experimental as temperaturas foram medidas continuamente através de sensores de temperatura.

Figura 3 - (a) Placa do sistema de aquisição de dados dos sensores de temperatura. (b)

Curva de calibração de um dos sensores de temperaturas. O valor do coeficiente de determinação $\left(R^{2}\right)$ revela a confiabilidade das medidas dos sensores quando comparadas com as leituras de um termômetro analógico de mercúrio
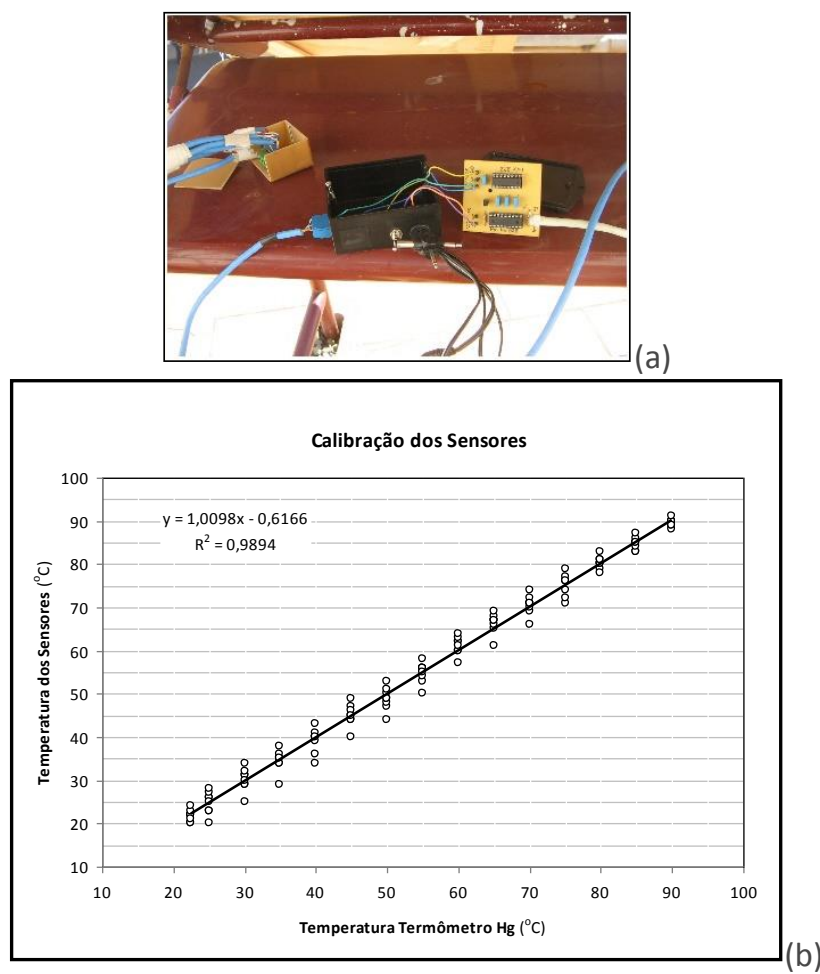

Para avaliar a eficiência térmica de um coletor solar deve-se conhecer a energia solar efetivamente absorvida pela superfície do mesmo. Neste caso, é recomendável utilizar um medidor de radiação solar. No presente trabalho, optouse por medir essa radiação com um Solarímetro, ou pirômetro (modelo: CMP22; intervalo espectral: $200 \mathrm{~nm}$ a $3600 \mathrm{~nm}$; intervalo da radiação solar: 0 a 4000 [W/ $\left.\mathrm{m}^{2}\right]$; resolução de $5,0\left[\mathrm{~W} / \mathrm{m}^{2}\right]$; precisão de $\pm 5 \%$; fabricante: Kipp \& Zonen, (KIPP \& ZONEN, 2012)), instalado ao lado do coletor solar, como mostrado na Figura 4a. 
Como a ação do vento também é um fator importante na determinação da eficiência de um aquecedor solar, uma vez que este dispositivo fica, normalmente, exposto ao ar livre, decidiu-se medir a velocidade do vento incidente na bancada de ensaios. Para tanto, foi utilizado uma estação meteorológica automática com Anemômetro de conchas da marca (modelo: WS-2080-A; wireless; intervalo de operação: 0 a 50 [m/s]; precisão de leitura de $\pm 0,04[\mathrm{~m} / \mathrm{s}]$; direção do vento: 0 $360^{\circ}$; faixa de temperatura para operação: -40 a $+65^{\circ} \mathrm{C}$; fabricante: Ambient Weather (AW, 2013)), também montado ao lado dos aquecedores como mostrado na Figura 4b.

Figura 4 - Detalhes do posicionamento final do (a) Solarímetro e (b) Anemômetro, colocados sobre e ao lado da bancada de ensaios, respectivamente
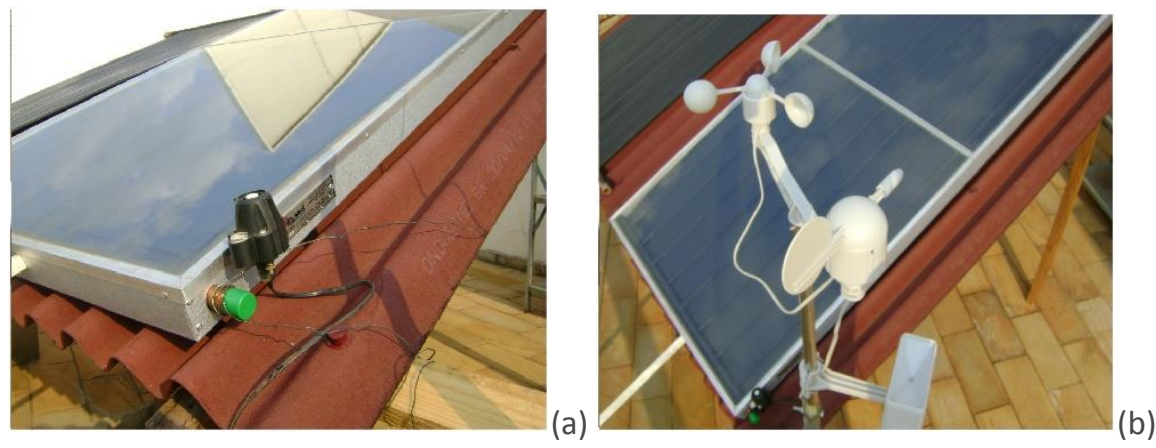

Além desses dispositivos, no sentido de estabelecer uma quantidade de vento com velocidade controlada, utilizou-se um ventilador elétrico de grande porte (marca Muntler, com dimensão de 1,40 x 1,40 m). Este dispositivo foi conectado a um gerador de frequências possibilitando o controle da velocidade de rotação do motor e, consequentemente, a velocidade do vento incidente na bancada de ensaios.

Tanto o Solarímetro como o Anemômetro foram calibrados obedecendo as informações contidas nos manuais técnicos desses respectivos equipamentos. Ambos foram conectados a um microcomputador tipo PC, usando uma placa microcontroladora de comunicação do tipo ARDUINO (modelo: Duemilanove 2009 AVR ATmega328, (ARDUINO, 2012)), o que possibilitou registrar todas medições durante cada ensaio experimental.

Além desses dispositivos de medições, informações relativas à temperatura ambiente, umidade relativa do ar, precipitação pluviométrica e pressão atmosférica foram coletadas de hora em hora ao longo de cada ensaio, por intermédio dos dados fornecidos via "on-line" no sistema do CEPAGRI-UNICAMP, na Estação Meteorológica Automática - Campus UNICAMP, por meio do acesso direto encontrado no endereço eletrônico: www.cpa.unicamp.br. Esse centro de pesquisa foi escolhido por se encontrar a menos de $3 \mathrm{~km}$ do local onde foi instalada a bancada de ensaios, favorecendo as comparações de dados climáticos no momento das medições experimentais.

Para o controle dos instrumentos descritos acima e a aquisição dos dados das grandezas físicas de interesse, foi desenvolvido um procedimento computacional específico para o reconhecimento dos sensores de temperaturas, do Solarímetro, e do Anemômetro. Adicionalmente, o citado procedimento registra as leituras das medições efetuadas por esses dispositivos. Desenvolvido em programação PYTHON e utilizando o ambiente de desenvolvimento ECLIPSE, o procedimento 
computacional reconhece cada dispositivo empregado através das portas USB, para o ARDUINO, e RS232, para a placa microcontroladora dos sensores de temperaturas. Além de reconhecer o sinal de cada dispositivo, interpreta o valor da medição num determinado instante e constrói o gráfico, bem como atualiza um arquivo de dados contendo informações do horário e os valores de todas as medições das temperaturas, velocidade de vento e radiação solar, todas realizadas em intervalos de tempo pré-definido.

Todas as medições realizadas foram armazenadas em arquivos do programa Microsoft Excel para, posteriormente, serem elaborados os gráficos relacionando a eficiência térmica do coletor solar. Um exemplo da tela do sistema de aquisição dos dados em operação está mostrado na Figura 5. Na figura é possível identificar os gráficos gerados por cada sensor de temperatura (à esquerda e ao centro), pelo Solarímetro (em cima, à direita) e pelo Anemômetro (no meio e à direita). A medida e o cálculo da eficiência térmica instantânea de cada aquecedor solar empregado estão visíveis na figura, posicionados abaixo e à direita, juntamente com as informações do CEPAGRI-UNICAMP. Todas essas informações são importantes para o posterior processo de redução de dados.

Figura 5 - Ilustração da tela do programa PYTHON para o procedimento de aquisição de dados dos coletores solares num determinado ensaio experimental

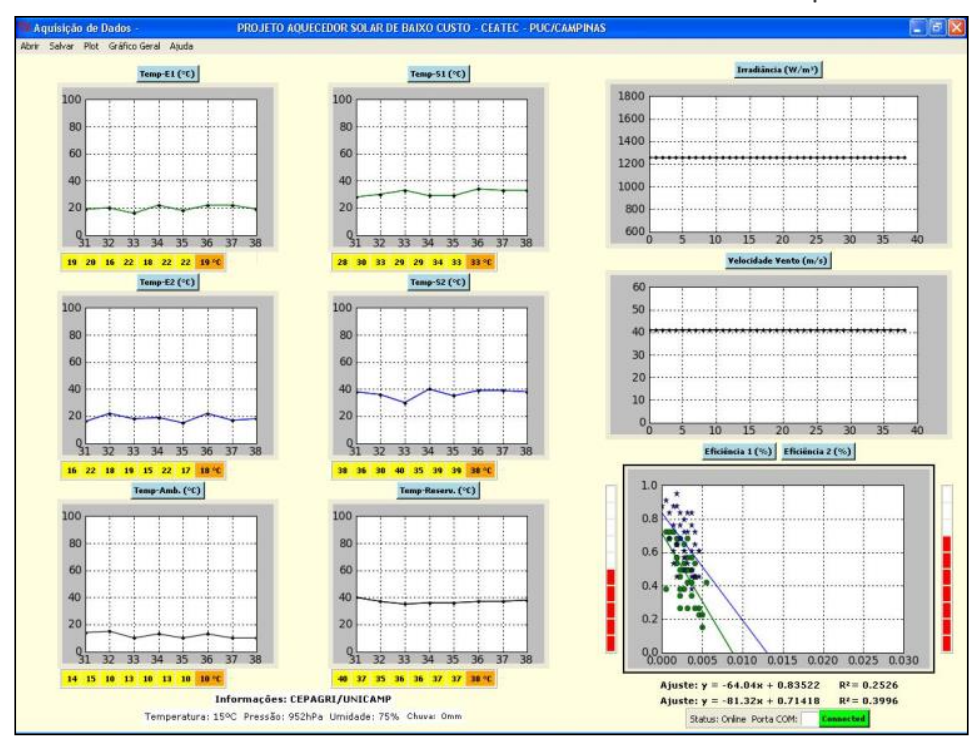

\section{RESULTADOS EXPERIMENTAIS}

Embora o objetivo de um aquecedor solar seja apenas o de obter água aquecida no reservatório para uso doméstico e/ou industrial, os coletores solares montados sobre a bancada de ensaios descrita acima têm como objetivo específico o de realizar medições quantitativas para inferir suas eficiências térmicas. As seções seguintes têm o intuito de expor como esses procedimentos foram realizados a partir de vários ensaios experimentais. 


\section{ANÁLISE DAS EFICIÊNCIAS DOS COLETORES SOLARES}

Os ensaios e as coletas das medidas de temperaturas, da radiação solar e do vento incidente nos coletores solares sobre a bancada, atuando na forma de um circuito térmico fechado, permitem identificar leis básicas da termodinâmica, bem como os princípios integrados de transmissão de calor. Resumidamente, pode-se dividir em quatro partes o sistema de aquecimento aqui utilizado: (a) captação da energia solar; (b) aquecimento da água pelos coletores; (c) transporte da água entre os coletores e o reservatório e (d) o armazenamento da água.

Vale lembrar que outras parcelas do calor transferido são perdidas para o ambiente e por meio dos próprios materiais com que foram feitos os coletores solares. Neste contexto, vários trabalhos desenvolvidos sobre esse assunto têm demonstrado a impraticabilidade de se considerar a totalidade das variáveis que possam influenciar no funcionamento do aquecedor, pelo fato de tais variáveis não exercerem influência significativa no comportamento do equipamento, podendo, por isso, serem em parte negligenciadas (ARAÚJO; ABIB, 2003; ARRUDA, 2004).

Nesse estudo foi considerada apenas uma parcela da radiação no coletor que é de fato utilizável para o aquecimento da água. Essa energia útil pode ser avaliada pelo ganho de calor que a água tem, devido à circulação do fluído nos coletores, por meio da equação:

$$
Q=\dot{m} \cdot C \cdot\left(T_{2}-T_{1}\right)
$$

em que $Q_{u}$ representa o fluxo de energia que chega ao reservatório [W]; $\dot{m}$ é a vazão de massa de água [kg/s]; $C$ é o calor específico da água como sendo igual a 4,18605 [J/kg $\left.{ }^{\circ} \mathrm{C}\right] ; T_{2}$ e $T_{1}$ são as temperaturas $\left[{ }^{\circ} \mathrm{C}\right]$ da água na saída e entrada do reservatório, respectivamente.

Para a eficiência térmica teórica $\left(\eta_{\text {Teórico }}\right)$ de um coletor solar pode-se empregar uma relação que envolve a energia útil do sistema $\left(Q_{u}\right)$ e que está relacionada à radiação solar incidente $\left(I_{t}\right)$, além da área do coletor $\left(A_{c}\right)$, dada pela equação (DUFFIE; BECKMAN, 1991; ARRUDA, 2004):

$$
\eta_{\text {Teórico }}=\frac{\int_{0}^{t} Q_{u} \cdot d t}{A_{c} \int_{0}^{t} I_{t} \cdot d t}=\frac{\dot{m} \cdot C \cdot\left(T_{2}-T_{1}\right)}{G_{T}}
$$

O termo $G_{T}$ é o produto de $A_{c} \operatorname{com} I_{T}$, representando a radiação total incidente $[\mathrm{W}]$ num determinado coletor.

A medida da eficiência térmica instantânea $(\eta)$ de um coletor solar pode ser extraída pelo balanço de energia e é dada em função das temperaturas. Essa informação pode ser obtida pela relação (DUFFIE; BECKMAN, 1991):

$$
\eta=F r \cdot(\tau \alpha)-F r \cdot U_{L}\left(\frac{T_{\exp }-T_{a m b}}{G_{T}}\right)
$$


O termo $T_{a m b}$ refere-se à temperatura do meio ambiente, enquanto que $T_{\exp }$ é a temperatura experimental. Esta última pode ser tomada como sendo a temperatura de entrada $\left(T_{1}\right)$ ou a de saída $\left(T_{2}\right)$ do fluido, ou ainda a média entre elas $\left(T_{\text {med }}\right)$. O termo $U_{L}$ o fator global de transferência de calor. Enquanto que $\mathrm{Fr}$ expressa o fator de remoção de calor, isto é, a quantidade real de calor absorvida e a máxima quantidade de calor possível que pode ser transferido. Este fator depende do coeficiente de correção $(\tau \alpha)$, sendo $\tau$ a transmitância e $\alpha$ a absortância do material empregado (ASHRAE, 1996).

Assim, a eficiência térmica pode ser entendida como uma medida inversamente proporcional à diferença entre as temperaturas, isto é, quanto maior for essa diferença, menor a eficiência medida. Este, no entanto, não é o único fator a ser considerado no cálculo da eficiência. O tipo de superfície absorvedora, o número de coberturas transparentes, a intensidade da irradiação solar, o isolamento térmico empregado no coletor, as velocidades do vento, dentre outros, exercem influências na determinação da eficiência do aquecedor solar.

Os resultados podem ser apresentados em formas gráficas fazendo $\eta$ em função de $\left[\left(T_{e}-T_{a m b}\right) / G_{T}\right]$. Essa maneira de atuar possibilita caracterizar um coletor por meio de curvas obtidas diretamente dos dados experimentais, da eficiência térmica instantânea $(\eta)$ como função das três variáveis $\left(T_{e}, T_{a m b}\right.$ e $\left.G_{T}\right)$, sendo $T_{a m b}$ a temperatura do meio ambiente no instante de cada medição.

Com os aparelhos e instrumentos utilizados para as análises numéricas realizadas nesse trabalho foi possível obter as seguintes imprecisões das grandezas envolvidas:

a) temperatura de entrada de água no coletor e a temperatura ambiente, $T_{e}$ e $T_{a m b}$, respectivamente: $\pm 0,1\left[{ }^{\circ} \mathrm{C}\right]$;

b) diferença de temperatura entre a entrada e saída do coletor, $T_{s}-T_{e}$ : $\pm 0,1\left[{ }^{\circ} \mathrm{C}\right]$;

c) vazão de água no coletor, $\dot{m}: \pm 1,0 \%[\mathrm{~kg} / \mathrm{s}]$;

d) área dos coletores, $A_{c}: \pm 0,01\left[\mathrm{~m}^{2}\right]$;

e) velocidade do vento, $V_{v}, \pm 2 \%[\mathrm{~m} / \mathrm{s}]$;

f) radiação solar, $I_{t}, \pm 10\left[\mathrm{Wm}^{-2}\right]$.

Cada ponto de ensaio na determinação da eficiência térmica está relacionado com seu respectivo desvio padrão, expresso por:

$$
\frac{\sigma_{\eta}}{\eta}= \pm \sqrt{\left(\frac{\sigma_{1}}{T_{e}-T_{s}}\right)^{2}+\left(\frac{\sigma_{2}}{\dot{m}}\right)^{2}+\left(\frac{\sigma_{3}}{A_{c}}\right)^{2}+\left(\frac{\sigma_{4}}{I_{T}}\right)^{2}}
$$

em que $\sigma_{n},(n=0,1, \ldots, 4)$ é o desvio da grandeza presente no respectivo denominador da fração.

Definindo a variável $T^{*}$ que, no caso, representa o eixo das abscissas nos gráficos $\left[\left(T_{e}-T_{a m b}\right) / G_{T}\right]$, para cada ponto usou-se a expressão: 


$$
\frac{\sigma_{T^{*}}}{T^{*}}= \pm \sqrt{\left(\frac{\sigma_{T_{1}^{*}}}{T_{e}-T_{a m b}}\right)^{2}+\left(\frac{\sigma_{T_{2}^{*}}}{G_{T}}\right)^{2}}
$$

com $\sigma_{T_{1}^{*}}$ e $\sigma_{T_{2}^{*}}$ sendo os respectivos desvio padrão de cada grandeza envolvida nos denominadores.

Um exemplo de uma coleta de medidas experimentais, realizadas a cada vinte minutos, para o ensaio realizado no dia 18/jan/13 entre as 09h00 e $16 \mathrm{~h} 20$ no horário oficial de verão, com um índice de vazão fixado em 0,020 [Kg/s] e para a velocidade de vento atuando no intervalo entre 1,00 a 1,50 [m/s], está mostrado na Tabela 1. Nessa tabela cada termo refere-se ao instante de cada medição.

Tabela 1 - Exemplo de medidas coletadas para a determinação da eficiência instantânea para o ensaio realizado em 18/jan/13 com faixa de velocidade de vento entre 1,00 e 1,51 $[\mathrm{m} / \mathrm{s}]$

\begin{tabular}{|c|c|c|c|c|c|c|}
\hline Hora & $\begin{array}{c}\mathrm{T}_{\mathrm{e}}-\mathrm{T}_{\mathrm{Tmb}} \\
\left({ }^{\circ} \mathrm{C}\right)\end{array}$ & $\begin{array}{l}\mathrm{T}_{\mathrm{s}}-\mathrm{T}_{\mathrm{e}} \\
\left({ }^{\circ} \mathrm{C}\right)\end{array}$ & $\begin{array}{c}I_{t} \\
\left(W / m^{2}\right)\end{array}$ & $\begin{array}{c}T^{*} \pm \sigma_{T^{*}} \\
\left({ }^{\circ} \mathrm{Cm}^{2} / \mathrm{W}\right)\end{array}$ & $\begin{array}{c}\eta \pm \sigma_{\eta}(P \vee C) \\
(\%)\end{array}$ & $\begin{array}{c}\eta \pm \sigma_{\eta}(M E T A L) \\
(\%)\end{array}$ \\
\hline 09:00 & 1,57 & 14,78 & 973,10 & $0,00216 \pm 0,064$ & $0,6081 \pm 0,016$ & $0,7324 \pm 0,016$ \\
\hline 09:20 & 1,51 & 17,72 & 1074,79 & $0,00140 \pm 0,060$ & $0,5876 \pm 0,022$ & $0,7302 \pm 0,019$ \\
\hline 09:40 & 1,33 & 13,96 & 951,99 & $0,00139 \pm 0,075$ & $0,5711 \pm 0,016$ & $0,6808 \pm 0,018$ \\
\hline $10: 00$ & 0,78 & 10,02 & 752,11 & $0,00289 \pm 0,012$ & $0,5649 \pm 0,016$ & $0,7102 \pm 0,026$ \\
\hline $10: 20$ & 2,40 & 11,24 & 881,51 & $0,00272 \pm 0,043$ & $0,5256 \pm 0,015$ & $0,6989 \pm 0,015$ \\
\hline $10: 40$ & 4,32 & 13,53 & 1049,80 & $0,00395 \pm 0,025$ & $0,4355 \pm 0,019$ & $0,6432 \pm 0,018$ \\
\hline $11: 00$ & 3,35 & 14,04 & 929,77 & $0,00383 \pm 0,031$ & $0,5227 \pm 0,016$ & $0,6909 \pm 0,020$ \\
\hline $11: 20$ & 9,47 & 3,71 & 647,53 & $0,01450 \pm 0,018$ & $0,5311 \pm 0,015$ & $0,5423 \pm 0,019$ \\
\hline $11: 40$ & 6,52 & 6,32 & 723,14 & $0,01044 \pm 0,021$ & $0,4274 \pm 0,032$ & $0,6051 \pm 0,026$ \\
\hline $12: 00$ & 14,64 & 6,38 & 841,89 & $0,01738 \pm 0,013$ & $0,3722 \pm 0,016$ & $0,5781 \pm 0,022$ \\
\hline $12: 20$ & 9,21 & 4,95 & 833,46 & $0,01105 \pm 0,015$ & $0,4254 \pm 0,023$ & $0,5907 \pm 0,021$ \\
\hline $12: 40$ & 0,84 & 13,76 & 1065,33 & $0,00126 \pm 0,011$ & $0,3926 \pm 0,023$ & $0,5703 \pm 0,016$ \\
\hline $13: 00$ & 2,52 & 16,15 & 1024,90 & $0,00371 \pm 0,040$ & $0,3640 \pm 0,025$ & $0,5602 \pm 0,015$ \\
\hline $13: 20$ & 4,83 & 12,71 & 1048,62 & $0,00541 \pm 0,022$ & $0,3212 \pm 0,015$ & $0,5431 \pm 0,018$ \\
\hline $13: 40$ & 9,65 & 9,67 & 1016,34 & $0,01046 \pm 0,013$ & $0,4707 \pm 0,022$ & $0,5199 \pm 0,020$ \\
\hline $14: 00$ & 9,75 & 9,13 & 973503 & $0,01036 \pm 0,014$ & $0,3488 \pm 0,016$ & $0,4772 \pm 0,017$ \\
\hline $14: 20$ & 12,90 & 5,54 & 849,32 & $0,01535 \pm 0,014$ & $0,2913 \pm 0,017$ & $0,4823 \pm 0,016$ \\
\hline $14: 40$ & 15,48 & 2,34 & 765,98 & $0,02049 \pm 0,014$ & $0,3491 \pm 0,016$ & $0,4678 \pm 0,016$ \\
\hline $15: 00$ & 2,32 & 10,10 & 1038,30 & $0,00276 \pm 0,044$ & $0,4508 \pm 0,018$ & $0,4422 \pm 0,015$ \\
\hline $15: 20$ & 1,37 & 13,70 & 1065,11 & $0,00174 \pm 0,073$ & $0,3595 \pm 0,015$ & $0,4222 \pm 0,019$ \\
\hline $15: 30$ & 3,13 & 12,75 & 961,93 & $0,00371 \pm 0,033$ & $0,2507 \pm 0,046$ & $0,3801 \pm 0,016$ \\
\hline $16: 00$ & 7,15 & 10,11 & 896,71 & $0,00754 \pm 0,018$ & $0,2211 \pm 0,016$ & $0,3601 \pm 0,021$ \\
\hline $16: 20$ & 12,61 & 17,86 & 851,56 & $0,00378 \pm 0,014$ & $0,2304 \pm 0,018$ & $0,3489 \pm 0,018$ \\
\hline
\end{tabular}


enquanto que para o valor do desvio padrão da grandeza $\left[\left(T_{e}-T_{a m b}\right) / G_{T}\right]$ adotouse expressão de $\left(\sigma_{T^{*}}\right.$ ) dado pela equação (5). Posteriormente, essas informações foram usadas nas confecções de gráficos e nos cálculos do desempenho do aquecedor, descritos a seguir.

Ao realizar os cálculos contidos na tabela verificou-se que a maior fonte de incerteza sobre os valores de $(\eta)$ de cada coletor solar se deve a medida de $I_{t}$, uma vez que essa informação foi extraída diretamente do sinal registrado pelo Solarímetro. Outra fonte de incerteza está relacionada às medidas das temperaturas, pois a placa controladora de aquisição conectada ao microcomputador (Figura 3a) oferece erros cumulativos. Os cálculos empregando a equação (5) revelaram valores para os desvios padrão da diferença de temperaturas e da eficiência, em cada ponto ensaiado, menores que $\pm 7,5 \%$, como indicam as respectivas colunas da tabela associadas a essas grandezas.

A etapa seguinte foi utilizar as informações numéricas contidas em tabelas, semelhantes à descrita acima, nas confecções de gráficos que visam à determinação da eficiência térmica efetiva de cada coletor solar em diferentes ensaios.

\section{CARACTERIZAÇÃO DOS COLETORES SOLARES}

Para realizar a caracterização de um determinado coletor solar adotou-se um método alternativo ao proposto por Duffie e Beckman (1991). Segundo esses autores é necessário utilizar alguns parâmetros físicos, dentre eles, como um coletor absorve a irradiação solar e quais as perdas do calor dissipado pelo dispositivo para o meio ambiente. Os parâmetros relacionados à espessura da placa com que é feito o coletor, o espaçamento da tubulação, as dimensões do isolamento térmico, dentre outros, não foram consideradas nas análises do presente trabalho.

Diante dessas simplificações, a eficiência térmica instantânea do equipamento $(\eta)$ está relacionada com a diferença de temperaturas $\left(T_{e}-T_{a m b}\right)$, além dos parâmetros que foram propostos por Duffie e Beckman (1991), além de Netto (2006), por meio da relação:

$$
\eta=F r \cdot(\tau \alpha)-F r \cdot U_{L}\left(\frac{T_{e}-T_{a m b}}{G_{T}}\right)
$$

Como comentado anteriormente, o termo $F_{r}(\tau \alpha)$ representa a parcela de energia radiante absorvida pelo coletor solar e depende do coeficiente de correção $(\tau \alpha)$, sendo: $\tau$ a transmitância e $\alpha$ a absortância do material empregado (ASHRAE, 1996). No entanto, o termo $F_{r} U_{L}$ representa o fator global de transferência de calor que representa as perdas para o meio ambiente. São esses dois parâmetros, $F_{r} U_{L}$ e $F_{r}(\tau \alpha)$, que caracterizam fisicamente um coletor solar. A título de comparação, para coletores solares feitos em cobre e alumínio, possuindo cobertura de vidro, os valores típicos encontrados na literatura para $F_{r} U_{L}$ e $F_{r}(\tau \alpha)$ são $7,7\left[\mathrm{~W} / \mathrm{m}^{2} \mathrm{~K}\right]$ e $0,74\left[\mathrm{~W} / \mathrm{m}^{2} \mathrm{~K}\right]$, respectivamente. No entanto, coletores solares de baixo custo sem cobertura e feitos de perfis extrudados de 
PVC, como o aqui empregado, apresentam desempenho satisfatório com valores de $16,0\left[\mathrm{~W} / \mathrm{m}^{2} \mathrm{~K}\right]$ para $F_{r} U_{L}$ e 0,61 $\left[\mathrm{W} / \mathrm{m}^{2} \mathrm{~K}\right]$ para $F_{r}(\tau \alpha)(\mathrm{MVEH}, 2000)$.

A partir dos cálculos realizados para a eficiência térmica instantânea $(\eta)$, medidos a partir da equação (2) e listados na Tabela 1, foi possível extrair uma relação entre a "Eficiência Instantânea versus $\left[\left(T_{e}-T_{a m b}\right) / G_{T}\right]$ ", empregando a equação (6), para o ensaio realizado em 18/jan/2013, sob as condições de vento com velocidades variando entre 1,00 a 1,50 [m/s]. Isso foi realizado por intermédio do gráfico, onde todos os cálculos foram elaborados em planilhas do Microsoft Excel, como o mostrado na Figura 6. Nesse tipo de gráfico é possível verificar como esses parâmetros se relacionam, nas condições climáticas vigentes por ocasião do ensaio experimental.

Figura 6 - Curvas da eficiência térmica instantânea $(\eta)$ versus $\left[\left(T_{e}-T_{a m b}\right) / G_{T}\right]$, para os coletores de PVC (azul) e de Metal (vermelho) no ensaio realizado em 18/jan/2013. Os dados estão listados na Tabela 1 e foram coletados em condições de ventos com velocidades variando entre 1,00 a $1,50[\mathrm{~m} / \mathrm{s}]$

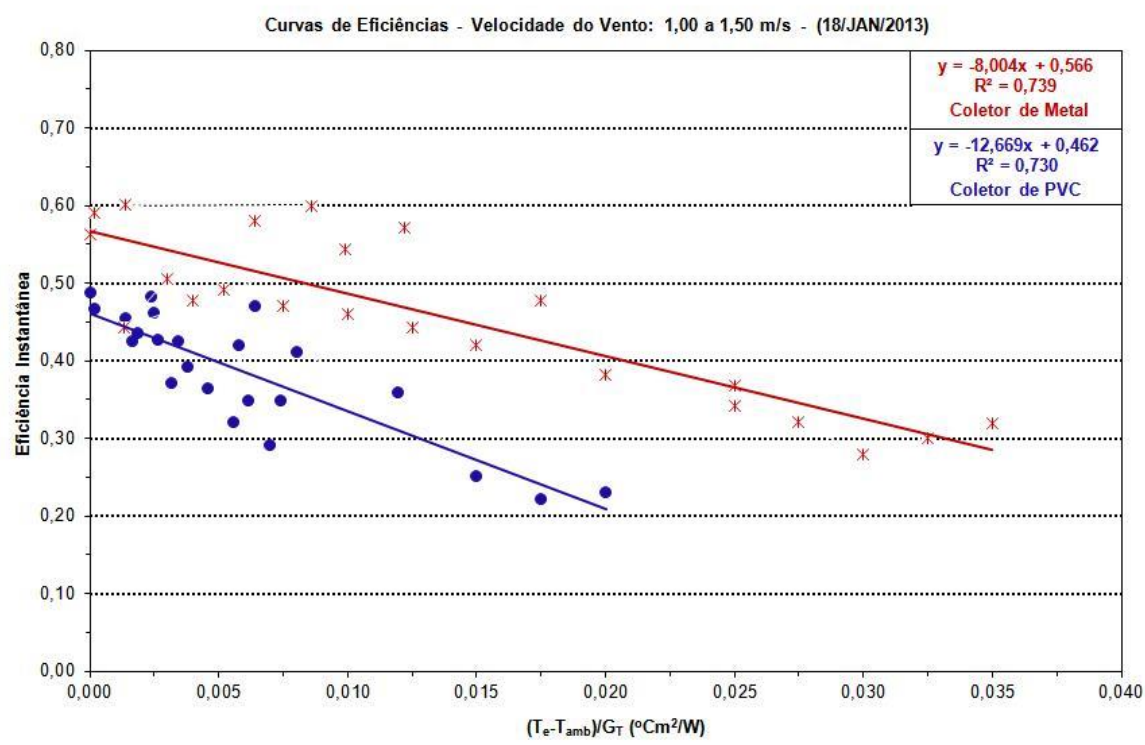

Usando a ferramenta "Análise de Tendência" no Excel, foram realizados os ajustes lineares mostrados na figura e extraídos os parâmetros térmicos $F_{r}(\tau \alpha)$ e $F_{r} U_{L}$ de cada coletor aqui discutido. As retas ajustadas nos gráficos interceptam o eixo vertical nos pontos $(0,0 ; 0,462)$ e $(0,0 ; 0,566)$, e representam as eficiências máximas instantâneas que os coletores de PVC e Metal apresentaram naquele ensaio (caracterizando para cada um o parâmetro $F_{r}(\tau \alpha)$ ), respectivamente. As inclinações das retas informam a respeito das perdas térmicas (que são caracterizadas pelos parâmetros $F_{r} U_{L}$ ). Podem ser inferidos a partir dos ajustes lineares e correspondem a $F r \cdot(\tau \alpha)=-12,669$ para o coletor de PVC e $\mathrm{Fr} \cdot U_{L}=-8,004$ para o de Metal. Esses valores, quando comparados aos trabalhos de Niemeyer (2006), Pereira et al. (2006) e Mveh (2000), indicam que as características físicas medidas para o coletor solar aqui desenvolvido são satisfatórias.

As Figuras 7a e 7b mostram os comportamentos das eficiências instantâneas dos coletores de PVC e Metal, respectivamente, adotando o mesmo método 
discutido acima, em diferentes ensaios realizados em condições de ventos com velocidades variando em intervalos entre 1,00 a 1,50 [m/s] (ajuste em verde); 1,51 a 2,00 [m/s] (ajuste em azul) e 2,01 a 2,50 [m/s] (ajuste em vermelho). Os ajustes lineares estão indicados nas laterais das figuras e revelam o valor da eficiência térmica em cada situação, além da qualidade dos ajustes por meio dos valores do teste estatístico $\left(R^{2}\right)$.

Figura 7 - Determinação das eficiências térmicas instantâneas $(\eta$ ) para: (a) coletor de PVC (superior) e (b) coletor de Metal (inferior) como dependência das velocidades de ventos. As medidas foram obtidas em vários dias ensaiados e em diferentes condições de ventos, com velocidades variando entre 1,00 a 1,50 [m/s] (ajustes em verde); 1,51 a 2,00 $[\mathrm{m} / \mathrm{s}]$ (ajustes em azul) e 2,01 a 2,50 [m/s] (ajustes em vermelho)
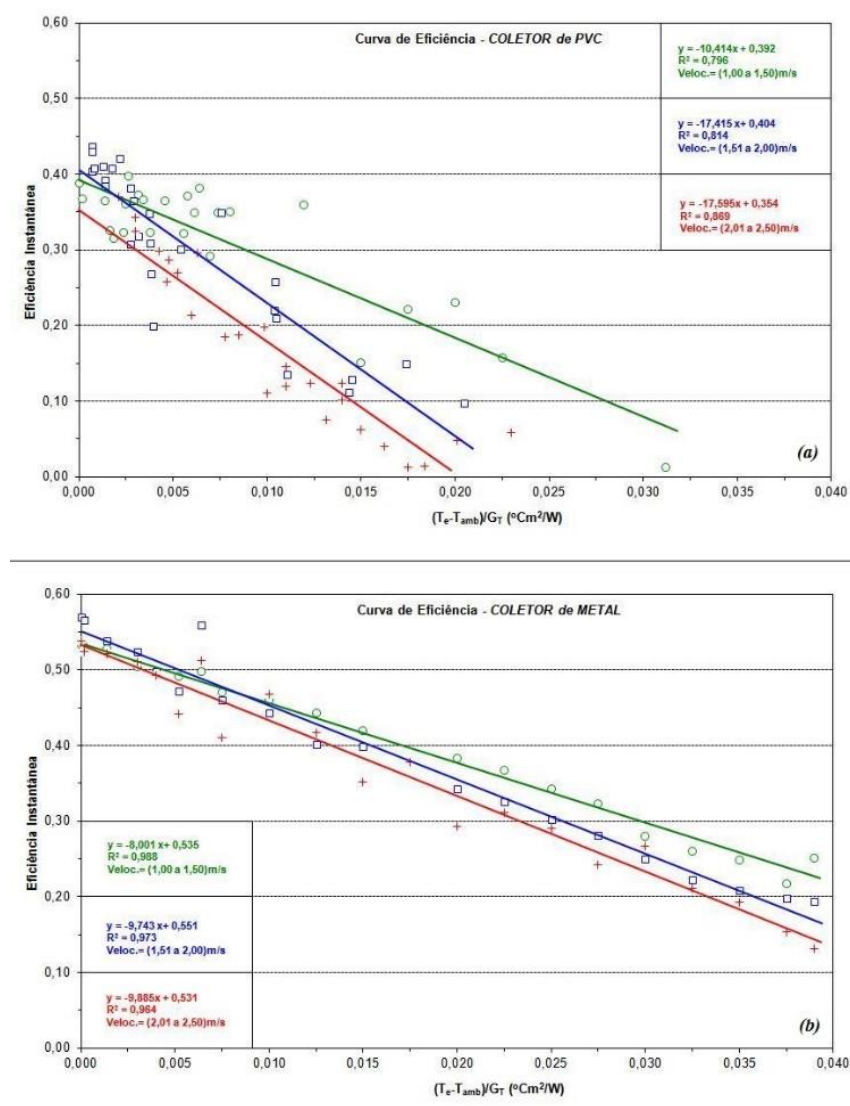

Realizando uma inspeção nesses gráficos é possível perceber a influência causada pelos ventos na determinação da eficiência térmica de cada coletor estudado. Como era de se esperar, os ventos mais intensos afetam de forma considerável o rendimento do coletor de PVC quando comparado ao de Metal. Isso pode ser constatado nos ajustes lineares realizados. Na Figura 7a, para o coletor de PVC, verifica-se que as retas ajustadas se afastam na medida em que a velocidade do vento aumenta, enquanto que na Figura $7 \mathrm{~b}$, para o coletor de Metal, isso não ocorre com tanta evidência. Uma possível explicação para esse fato é o uso da cobertura de vidro no coletor de Metal, que provoca um "efeito estufa", mantendo durante maior tempo a energia térmica no interior das tubulações que trocam essa energia com a água, evitando a perda energética devido a ação do vento para o meio ambiente. 
Durante os meses de outubro/2012 a fevereiro/2013 foram realizados vários ensaios independentes, onde sempre se procurou trabalhar em dias ensolarados e no período das 09 h00 às 17 h00. De forma análoga ao explicado nos ensaios acima descritos, obteve-se as eficiências térmicas instantâneas para os dois coletores simultaneamente, registrando as velocidades dos ventos incidentes em ambos, em cada dia ensaiado. Os ensaios foram direcionados visando coletas de dados nos três intervalos de velocidades descritos anteriormente, descartando aqueles dias que apresentaram ventos com medidas de velocidades fora dos intervalos previstos.

Analisando todos os gráficos dessas eficiências no período em que esse trabalho experimental foi desenvolvido, pode-se obter a eficiência térmica instantânea $(\eta)$ e o respectivo desvio padrão $\left(\sigma_{n}\right)$ dos coletores solares. As Tabelas 2, 3 e 4 mostram esses valores para cada ensaio realizado no período. Ao final de cada intervalo de velocidade encontram-se os valores da eficiência instantânea média $(\bar{\eta})$ e o desvio padrão dessa medida $\left(\sigma_{\bar{\eta}}\right)$. Na linha seguinte, a tabela mostra as eficiências médias totais e os desvios padrão associados ( $\bar{R} \pm \sigma_{\bar{R}}$ ) de cada coletor, no respectivo intervalo de velocidades do vento.

No intervalo de velocidades $1,00<\mathrm{V}_{\mathrm{v}}(\mathrm{m} / \mathrm{s})<1,50$, conforme mostra a Tabela 2 , foram realizados dez ensaios que acusaram valores de eficiência instantânea entre 0,39219 a 0,46192, com valor médio de 0,42536 $\pm 0,02714$ para o coletor de PVC. Nesse mesmo intervalo o coletor de Metal acusou eficiência instantânea entre 0,52319 a 0,56704, com valor médio de 0,55232 $\pm 0,01498$. As eficiências médias totais $\left(\bar{R} \pm \sigma_{\bar{R}}\right)$ calculadas foram $0,34 \pm 0,12$ e $0,44 \pm 0,10$ para os coletores de PVC e Metal, respectivamente.

Para o intervalo 1,51 $<\mathrm{V}_{\mathrm{v}}(\mathrm{m} / \mathrm{s})<2,00$, são informados nas linhas da Tabela 3, os valores dos parâmetros inferidos para os nove ensaios. Registraram-se valores de $\eta$ entre 0,37704 a 0,41323, com valor médio de 0,39685 $\pm 0,01285$ para o coletor de PVC, enquanto que para o coletor de Metal os valores de $\eta$ oscilaram entre 0,54418 a 0,55229, com valor médio de 0,54817 $\pm 0,00323$. Nesse caso, as eficiências médias totais $\left(\bar{R} \pm \sigma_{\bar{R}}\right)$ calculadas foram, para os coletores de PVC e

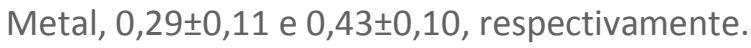

Tabela 2 - Medidas das eficiências térmicas dos coletores e respectivos desvios padrão para os ensaios realizados em condições dos ventos entre 1,00 a 1,50 [m/s]

\begin{tabular}{|c|c|c|c|c|c|}
\hline \multirow[b]{3}{*}{ Ensaio } & \multirow[b]{3}{*}{ Data } & \multicolumn{4}{|c|}{$1,00<V_{v}(m / s)<1,50$} \\
\hline & & \multicolumn{2}{|c|}{ PVC } & \multicolumn{2}{|c|}{ Metal } \\
\hline & & $\eta$ & $\sigma_{\eta}$ & $\eta$ & $\sigma_{\eta}$ \\
\hline 1 & 24/out/12 & 0,41542 & 0,07931 & 0,56627 & 0,04918 \\
\hline 2 & 06/nov/12 & 0,40016 & 0,08513 & 0,55631 & 0,05213 \\
\hline 3 & 08/nov/12 & 0,45692 & 0,08140 & 0,54378 & 0,04193 \\
\hline 4 & $12 /$ nov/12 & 0,44271 & 0,08568 & 0,56704 & 0,04568 \\
\hline 5 & $21 /$ nov/12 & 0,40418 & 0,07753 & 0,53518 & 0,04854 \\
\hline 6 & 04/dez/12 & 0,39219 & 0,08376 & 0,52319 & 0,05371 \\
\hline 7 & 11/dez/12 & 0,42432 & 0,07521 & 0,56489 & 0,04425 \\
\hline
\end{tabular}




\begin{tabular}{|c|c|c|c|c|c|}
\hline \multirow[b]{3}{*}{ Ensaio } & \multirow[b]{3}{*}{ Data } & \multicolumn{4}{|c|}{$1,00<V_{v}(m / s)<1,50$} \\
\hline & & \multicolumn{2}{|c|}{ PVC } & \multicolumn{2}{|c|}{ Metal } \\
\hline & & $\eta$ & $\sigma_{\eta}$ & $\eta$ & $\sigma_{\eta}$ \\
\hline 8 & 18/jan/13 & 0,46192 & 0,08343 & 0,56634 & 0,03243 \\
\hline 9 & 24/jan/13 & 0,39872 & 0,07623 & 0,54766 & 0,02826 \\
\hline 10 & 05/fev/13 & 0,45706 & 0,08949 & 0,55257 & 0,05846 \\
\hline \multicolumn{2}{|c|}{ Médias $\left(\bar{\eta} \pm \sigma_{\bar{\eta}}\right)=$} & 0,42536 & 0,02714 & 0,55232 & 0,01498 \\
\hline \multicolumn{2}{|c|}{$\left(\bar{R} \pm \sigma_{\bar{R}}\right)=$} & \multicolumn{2}{|c|}{$0,34 \pm 0,12$} & \multicolumn{2}{|c|}{$0,44 \pm 0,10$} \\
\hline
\end{tabular}

Apenas sete ensaios foram feitos com o intervalo de velocidades 2,01< $\mathrm{V}_{\mathrm{v}}(\mathrm{m} / \mathrm{s})<2,50$ (Tabela 4), registrando-se para o coletor de PVC valores de $\eta$ entre

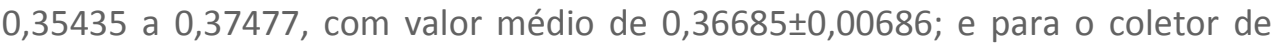
Metal valores de $\eta$ entre 0,53128 a 0,54928, com valor médio de $0,53995 \pm 0,00654$. As eficiências médias totais $\left(\bar{R} \pm \sigma_{\bar{R}}\right)$ calculadas nesses casos

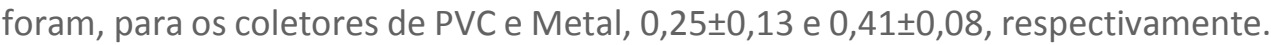

A Figura 8 mostra uma síntese dessas informações, onde, certamente, as variações nos valores inferidos para as eficiências instantâneas devem-se às variações das velocidades dos ventos aos quais os coletores se submeteram. Essa constatação pode ser comprovada tanto pelos dados da tabela como pelos ajustes mostrados nos gráficos dessa figura.

Tabela 3 - Idem a tabela anterior, mas para o intervalo dos ventos entre 1,51 a 2,00 [m/s]

\begin{tabular}{|c|c|c|c|c|c|}
\hline \multirow[b]{3}{*}{ Ensaio } & \multirow[b]{3}{*}{ Data } & \multicolumn{4}{|c|}{$1,51<V_{v}(m / s)<2,00$} \\
\hline & & \multicolumn{2}{|c|}{ PVC } & \multicolumn{2}{|c|}{ Metal } \\
\hline & & $\eta$ & $\sigma_{\eta}$ & $\eta$ & $\sigma_{\eta}$ \\
\hline 1 & $30 /$ out/12 & 0,40434 & 0,07816 & 0,54568 & 0,03762 \\
\hline 2 & 07/nov/12 & 0,38698 & 0,08615 & 0,55229 & 0,05723 \\
\hline 3 & $13 /$ nov/12 & 0,40117 & 0,05463 & 0,54917 & 0,03511 \\
\hline 4 & $26 /$ nov/12 & 0,37702 & 0,06098 & 0,54506 & 0,04959 \\
\hline 5 & $12 / \mathrm{dez} / 12$ & 0,39610 & 0,07761 & 0,54418 & 0,05327 \\
\hline 6 & 18/dez/12 & 0,41323 & 0,07464 & 0,55221 & 0,03848 \\
\hline 7 & 22/jan/13 & 0,40389 & 0,05425 & 0,54607 & 0,05142 \\
\hline 8 & 25/jan/13 & 0,37982 & 0,06433 & 0,55163 & 0,05806 \\
\hline 9 & 06/fev/13 & 0,40902 & 0,07559 & 0,54721 & 0,03845 \\
\hline \multicolumn{2}{|c|}{ Médias $\left(\bar{\eta} \pm \sigma_{\bar{\eta}}\right)=$} & 0,39685 & 0,01285 & 0,54817 & 0,00323 \\
\hline \multicolumn{2}{|c|}{$\left(\bar{R} \pm \sigma_{\bar{R}}\right)=$} & \multicolumn{2}{|c|}{$0.29 \pm 0.11$} & \multicolumn{2}{|c|}{$0,43 \pm 0,10$} \\
\hline
\end{tabular}


Tabela 4 - Idem as tabelas anteriores, com o intervalo dos ventos entre 2,01 a 2,50 [m/s]

\begin{tabular}{|c|c|c|c|c|c|}
\hline \multirow[b]{3}{*}{ Ensaio } & \multirow[b]{3}{*}{ Data } & \multicolumn{4}{|c|}{$2,01<V_{v}(m / s)<2,50$} \\
\hline & & \multicolumn{2}{|c|}{ PVC } & \multicolumn{2}{|c|}{ Metal } \\
\hline & & $\eta$ & $\sigma_{\eta}$ & $\eta$ & $\sigma_{\eta}$ \\
\hline 1 & $20 /$ nov/12 & 0,36411 & 0,08357 & 0,54928 & 0,05138 \\
\hline 2 & $13 / \mathrm{dez} / 12$ & 0,36765 & 0,07563 & 0,53831 & 0,05804 \\
\hline 3 & 30/jan/12 & 0,37376 & 0,08054 & 0,53557 & 0,04971 \\
\hline 4 & 16/jan/12 & 0,37477 & 0,08779 & 0,54704 & 0,05122 \\
\hline 5 & 29/jan/13 & 0,36854 & 0,08241 & 0,53588 & 0,04892 \\
\hline 6 & $01 / \mathrm{fev} / 13$ & 0,35435 & 0,07215 & 0,54230 & 0,05379 \\
\hline 7 & 20/fev/13 & 0,36476 & 0,08011 & 0,53128 & 0,06083 \\
\hline \multicolumn{2}{|c|}{ Médias $\left(\bar{\eta} \pm \sigma_{\bar{\eta}}\right)=$} & 0,36685 & 0,00686 & 0,53995 & 0,00654 \\
\hline \multicolumn{2}{|c|}{$\left(\bar{R} \pm \sigma_{\bar{R}}\right)=$} & \multicolumn{2}{|c|}{$0,25 \pm 0,13$} & \multicolumn{2}{|c|}{$0,41 \pm 0,08$} \\
\hline
\end{tabular}

Além disso, os gráficos indicam que na medida em que aumenta o intervalo da velocidade do vento a eficiência média instantânea $(\bar{\eta})$ do coletor de Metal não foi muito afetada, ficando em $(54,68 \pm 0,82) \%$. Entretanto, para o coletor de PVC ocorreram maiores variações do $\bar{\eta}$, acusando um valor de $(39,64 \pm 1,56) \%$. 
Figura 8 - Curvas das eficiências térmicas médias totais do coletor solar de Metal (reta tracejada) e de PVC (reta contínua) devido à influência da velocidade do vento nos três intervalos estudados nesse trabalho. Os valores médios e os respectivos desvios padrão estão assinalados à direita de cada ajuste linear
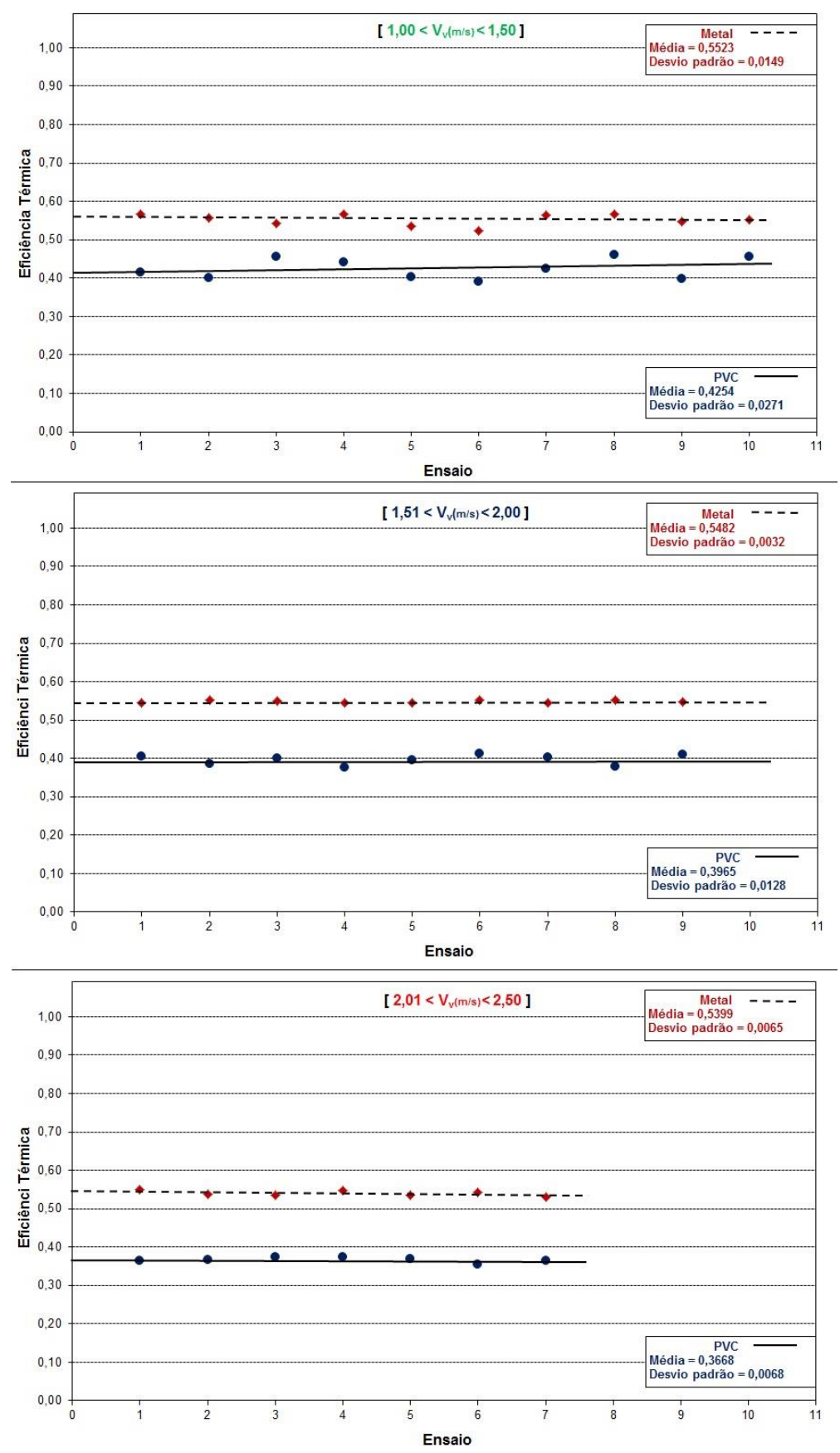

Um fato marcante na análise da figura está no comportamento dos ajustes realizados para as eficiências médias totais $\left(\bar{R} \pm \sigma_{\bar{R}}\right)$. Verifica-se que, na medida em que a velocidade do vento é incrementada, os ajustes feitos aos dados do coletor de PVC se afastam gradativamente dos ajustes envolvendo os dados do coletor de Metal. Novamente, pode-se justificar esse comportamento devido ao "efeito estufa" causado pela cobertura de vidro. 
Em que pese a maior eficiência térmica do coletor de Metal, frente ao de PVC, constata-se que a eficiência média total desse último é considerada satisfatória, pois a diferença dessa grandeza entre os dispositivos aqui analisados ficou em $14,4 \%$. Não obstante, tendo em vista as dispersões dos pontos produzidos pelas variações das velocidades do vento e pela sensibilidade de cada coletor analisado a estas variações, os resultados obtidos podem ser considerados satisfatórios e úteis para trabalhos futuros no sentido de realizar outras comparações em situações climáticas diferenciadas e com materiais diferentes.

\section{CONSIDERAÇÕES FINAIS}

A construção e utilização de um coletor solar plano de baixo custo permitem a exploração qualitativa e quantitativa de vários conceitos da física básica e moderna que podem ser discutidos com os estudantes de um curso de Engenharia (em particular os cursos de engenharia: ambiental, civil, elétrica, mecânica e computação), além de disciplinas de ciência no Ensino Médio. Estes estudos permitem que o aluno compreenda a importância de estudos teóricos para a otimização de aplicações técnicas, e serve como ferramenta para o professor poder discutir não apenas os aspectos técnicos envolvidos, mas também trabalhar seu papel de formador de cidadãos (ARAUJO; ABIB, 2003). Neste aspecto, é possível explorar e discutir diversas fontes alternativas de energias e os impactos ambientais eventualmente deixados pelo uso destas, além de mencionar e esclarecer que o consumo de energia elétrica pode ser reduzido em até aproximadamente $40 \%$ com o uso de coletor solar de baixo custo em substituição ao tradicional chuveiro elétrico.

Embora na prática o que se obtém com os equipamentos aqui discutidos seja apenas o aquecimento de água para uso em geral, para um resultado quantitativo do desempenho e da eficiência térmica de cada coletor solar, foram realizadas algumas medições termométricas empregando sensores de temperaturas em alguns pontos estratégicos por onde ocorre o fluxo de água nos equipamentos. Um desses sensores foi instalado dentro do reservatório, de modo que se pudesse medir a temperatura média $\left(T_{\text {med }}\right)$ da água do reservatório à medida que o tempo transcorria ao longo do dia.

Mesmo com as dificuldades encontradas para realizar o presente trabalho, principalmente devido às exigências que foram impostas, como atuar em condições climáticas favoráveis, operar em faixas determinadas de irradiação solar e de velocidade do vento pré-estabelecidas pelo uso de um ventilador de grande porte, controlar o fluxo adequado d'água, calibrar adequadamente e de forma uniforme todos os dispositivos de medições, usar as condições reais de operação dos sensores e dos próprios coletores, pode-se admitir que os objetivos propostos foram atingidos com sucesso.

Como foi possível verificar pelos dados das Tabelas 2, 3 e 4, uma elevada dispersão de pontos produzidos pela variação das velocidades do vento e pela sensibilidade de cada coletor a estas variações, porém os resultados obtidos para as eficiências térmicas instantânea, média e total, de ambos os dispositivos podem ser considerados satisfatórios, pois possibilitou a realização dos ensaios 
Os dados dessas tabelas e os gráficos dos comportamentos das eficiências instantâneas dos coletores de PVC e Metal, mostrados na Figura 8, revelam que no coletor de Metal com cobertura de vidro superou em 14,4\% a eficiência do coletor de PVC. A partir dessa figura, é possível concluir que quando se deseja apenas pouco aquecimento d'água com coletores feitos com materiais de baixo custo de pouco adianta utilizar uma cobertura de vidro, mesmo porque o "efeito estufa" provocado nos materiais utilizados (perfis extrutados e conexões de PVC, além da cola epóxi) provocaria sérios problemas, como torções e consequentes vazamentos, dentre outros.

Uma estimativa da eficiência térmica medida para o coletor solar de baixo custo indicou um valor de aproximadamente $40 \%$ de eficiência, o que está de acordo com os valores medidos por outros autores pesquisados na literatura (PEREIRA et al., 2006). Para Oliva (apud SPRENGER, 2007), aquecedores solares de baixo custo são considerados os sistemas de baixo investimento inicial, quando comparados aos aquecedores solares tradicionais do mercado, que possui um custo final da ordem de 5 a 6 vezes maior. Apesar de, em muitos casos, haver redução relativa do rendimento térmico medido ou, ainda, da vida útil.

Para novos estudos direcionados a esse assunto, sugere-se que haja um tempo mais prolongado de medições, de maneira a obter um maior número de pontos nas curvas de eficiência instantânea. Essa conduta possibilitará extrair um maior número de intervalos de velocidade de vento. Seria muito valioso realizar medidas com ambos coletores ao longo de todas as estações do ano, isso propiciaria verificar os comportamentos sazonais de ambos dispositivos e a influência da irradiação solar sobre os mesmos.

Um item importante desse trabalho é que o mesmo abre outros espaços para de pesquisas a serem realizadas futuramente. Dentre elas, realizar um estudo mais aprofundado da influência da vazão na eficiência de coletores solares e, juntamente, analisar se existe alguma relação do valor da constante de tempo do coletor com sua sensibilidade à vazão com a qual se opera. Outra opção seria o de desenvolver coberturas de baixo custo para coletores poliméricos com o propósito de aumentar a durabilidade desse tipo de equipamento. 


\title{
Measurements of thermal efficiencies in solar heaters: an alternative for teaching the concepts of physics to engineering students
}

\begin{abstract}
The present work describes the construction of two flat solar energy collectors, in order to make a comparative study of thermal energy, in function of the wind's velocity. One was made using low cost materials and can be easily acquired by population, while the order is a metal collector commercially available. This task carries as a goal the lining up of physics teaching and the knowledge involved in the construction and functioning of a solar water heater system. The work was carried on in a practical way with the concepts of temperature, solar radiation, heat, thermal efficiency, among others. In order to do it, an automatic temperature, solar radiation and wind velocity measuring system, intermediated by microcontrollers and interfaced with a microprocessor was developed. The answers curves, due the influence of wind's velocity, incident to measures of their thermal efficiencies for solar energy absorption, were lifted up from the two collectors. It was noticed that the metal collector is $14.4 \%$ more effective than low cost.
\end{abstract}

KEYWORDS: Efficiency measured. Wind influence. Low cost solar water heater. Closed-loop solar heaters. 


\section{NOTAS}

1 Disponível em: www.sociedadedosol.org.br.

\section{REFERÊNCIAS}

ANEEL - Agência Nacional de Energia Elétrica. Ambientalista pede maior uso da energia solar. Disponível em:

<http://www.agenciabrasil.gov.br/notícias/2007/06/04/materia.2007-0604.378672631/view>. Acesso em: 8/09/2013.

ARAÚJO, M. S.; ABIB, M. L. S. Atividades experimentais no ensino de física: diferentes enfoques, diferentes finalidades. Revista Brasileira de Ensino de Física, v. 25, n. 2, p. 176-194, 2003.

ARDUINO. Disponível em: <http://www.arduino.cc/>. Acesso em: 4/08/2012.

ARRUDA, L. B. Operação de sistemas de aquecimento solar de água com controle de vazões em coletores planos. Tese de Doutorado em Engenharia Civil - Escola Politécnica, USP, São Paulo, SP. 230p. 2004.

ASHRAE - American Society of Heating, Refrigerating and Air Conditioning Engineers. ASHRAE Handbook: heating, ventilating and air-conditioning systems and equipment. Atlanta. Cap. 33. 1996.

AW - Ambient Weather. WS-2080 Weather Station. Disponível em: <http://www.ambientweather.com/>. Acesso em: 4/04/2013.

DALLAS. Dallas Instruments. Semiconductor - DS1820 digital thermometer. Disponível em: <www.spezial.com/doc/maxim/ds18s20.pdf> Acesso em: 14/05/2013.

DUFFIE, J. A.; BECKMAN, W. A. Solar engineering of thermal processes. $2^{\mathrm{a}}$. ed. Wisconsin: John Wiley \& Sons, 1991.

ELETROBRÁS - Centrais Elétricas S.A. Avaliação do Mercado de Eficiência Energética no Brasil. Pesquisa de Posse de Equipamentos e Hábitos de Uso (ano base 2005). Classe Residencial - Relatório Brasil. Rio de Janeiro, RJ: julho/2007.

KIPP \& ZONEN - Standart Pyrometer. Disponível em: 
MVEH, J. D. B. M. Análise teórica e experimental da eficiência térmica de coletores solares sem cobertura e de baixo custo. Dissertação de Mestrado, PROMEC - Universidade Federal do Rio Grande do Sul - URFS, Porto Alegre, RS. 77 p. 2000

NETTO, C. Q. Análise de um pequeno sistema de aquecimento solar instalado no interior do Estado de Minas Gerais. Monografia do Departamento de Engenharia da UFLA, Lavras, MG. 41p. 2006.

NIEMEYER, R. C. Construção de um coletor solar inflável. TCC do Departamento de Engenharia Mecânica da UNB. Brasília, DF. 80p. 2006.

OLIVEIRA FILHO, K. S.; SARAIVA, M. F. O. Astronomia \& Astrofísica. 2ª ed. São Paulo: Editora Livraria da Física, 2004.

PEREIRA, R. C.; SHIOTA, R. T.; MELLO, S. F.; ASSIS JR., V.; BARTOLI, J. R. Eficiência térmica de coletores solares de baixo custo - CSBC. 17. CBECIMat, Anais... Foz do Iguaçu, PR. 2006.

SPRENGER, R. L. Aplicação do sistema fechado no aquecedor solar de água de baixo custo para reservatórios residenciais isolados termicamente: Concepção e comissionamento de um sistema-piloto de testes. Dissertação de mestrado em Engenharia Civil, UFPR, Curitiba. 107p. 2007.

Recebido: 25 jul. 2015.

Aprovado: $01 \mathrm{fev} .2016$.

DOI: $10.3895 /$ rbect.v9n1.1598

Como citar:

PENEREIRO, J. C. Medidas das eficiências térmicas em aquecedores solares: uma alternativa

complementar para o ensino de conceitos de física para estudantes das engenharias. Revista Brasileira de

Ensino de Ciência e Tecnologia, v. 9, n. 1, p. 99-122, jan./abr. 2016. Disponível em:

$<$ https://periodicos.utfpr.edu.br/rbect/article/view/1598>. Acesso em: xxx.

Correspondência:

Júlio César Penereiro

Rod. Dom Pedro I, Km 136, Campinas, São Paulo, Brasil.

Direito autoral: Este artigo está licenciado sob os termos da Licença Creative Commons-Atribuição 4.0

Internacional. 